\title{
Mental Models Of Groundwater Residence: A Deeper Understanding Of Students' Preconceptions As A Resource For Teaching And Learning About Groundwater And Aquifers
}

\author{
Leilani A. Arthurs, University of Colorado at Boulder, USA
} Justin M. Elwonger, University of Nebraska-Lincoln, USA

\begin{abstract}
There is a growing need for public understanding about groundwater resources. Knowing what groundwater and aquifers are is fundamental to understanding more complex issues such as groundwater quality and availability. However, groundwater and related concepts are among the topics that instructors most struggle to teach. Although constructivist theories suggest that students' preconceptions or misconceptions can be used as teaching tools, the question about exactly how remains. A resource perspective on this question states the first step involves understanding students' preconceptions. To gain a deeper understanding of college students' pre-instructional mental models about groundwater residence, 215 students enrolled in introductory-level environmental geoscience courses taught at two large US state universities were surveyed. An open-ended questionnaire asked participants to draw and label a concept sketch. Follow-up interviews asked participants to elaborate upon their concept sketches. Eight categories of mental models emerged from the analysis of the collected data. These results were interpreted through the lens of cognitive schema theory, which generated to four patterns of mental models. These patterns emphasize key aspects of students' pre-instructional mental models about groundwater residence. Instructors can use this information to design instructional activities about groundwater and aquifers using a resource perspective.
\end{abstract}

Keywords: Geology Education Research; Groundwater; Misconception

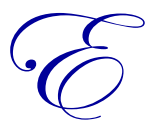

very state withdraws groundwater for a variety of uses (Maupin, et al. 2014) and more than $80 \%$ of people residing in the United States obtain drinking water from aquifers (Kenny, et al. 2009). Threats to the quality and quantity of drinking water from these sources come from, for example, agricultural and industrial contamination that leaks into the subsurface (Mackay \& Cherry, 1989; Wakida \& Lerner, 2005) as well as pumping aquifers at rates that keep pace with development but that exceed natural recharge rates (Oude Essink, 2001). An understanding of groundwater and aquifers is therefore among the "ideas of Earth Science that all citizens should know, determined by the Earth Science research and education communities [so that they are able to] make informed and responsible decisions regarding Earth and its resources" (Earth Science Literacy Initiative, 2009). However, previous research indicates that groundwater and related concepts are among content areas that instructors struggle to assist students in developing more expert-like conceptions (Hewson, 1981; Meyer, 1987).

Now widely accepted constructivist theories of learning state that new knowledge occurs when it is meaningfully linked to prior knowledge (Ausubel, 1968; Driver \& Erickson, 1983; Ausubel \& Ausubel, 2000; Patchen \& CoxPetersen, 2008; Powell \& Kalina, 2009; Tweed, 2009; Savasci \& Berlin, 2012). Although, instructors are sometimes inclined to attempt replacing prior knowledge that they view as wrong (Meyer, 2004), constructivist theories of learning support a resource perspective when it comes to interpreting and utilizing students' prior knowledge (Hammer, 2000). That is, instead of viewing students' prior knowledge as simply incorrect, instructors are challenged to use students' prior knowledge as conceptual resources that can be used to bridge students' current mental models 
towards more expert-like mental models (Hammer, 2000). A resource perspective has been applied to, for example, teaching students about forces (Brown, 1994; Hammer, 2000) but its application in teaching Earth science at the college level has not been documented at the college level.

Whereas "conceptual models are devised as tools for the understanding or teaching of ... systems [...], mental models are what people really have in their heads and what guides their use of things" (Norman, 1983, p. 12). Mental models that are incongruent with expert-defined mental models have been referred to as misconceptions (Helm, 1980), naïve (Clement, 1993; Kinchin, Hay, \& Adams, 2000), preconceptions (Arthurs, 2011; Novak, 1977; Clement, 1993), and alternate frameworks (Driver, 1981; Dal, 2007). For the purposes of this study, "preconception" is defined as prior knowledge or a mental model held before formal instruction during a given period of interest (Arthurs, 2011).

To enact a resource perspective in the context of teaching about groundwater and related concepts, instructors must first know something about students' preconceptions. A variety of methods are used to do mental models research, such as oral interviews, written responses, and concept sketching. Concept sketching (i.e., drawing one's ideas about a given concept) is a method for obtaining insights into student thinking that has a long and respected historical record (e.g., Piaget, 1956). Concept sketches are representations of the sketchers' mental models.

In the present study, concept sketching is used to more deeply understand students' preconceptions or pre-instructional mental models about groundwater residence. This exploratory study (Phase 1 of a larger project) was done for the express purpose of future work to design an instructional sequence about groundwater using a resource perspective (Phase 2 of a larger project). Groundwater residence was selected as the key concept for this study because students' preconceptions about how groundwater is naturally stored has implications for learning about aquifers and more advanced hydrological concepts such as groundwater flow, pumping, and recharge and discharge rates. The driving question that motivates this study is: What preconceptions do students have about groundwater residence? To address this question, the specific research questions for this study are:

(1) What kinds of pre-instructional mental models about groundwater residence exist among college students enrolled in introductory-level environmental geoscience courses at two different universities in the United States?

(2) How do these mental models compare to those reported in the literature?

(3) How can we interpret the identified mental models in a way that deepens our understanding of students' understanding of groundwater residence?

\section{THEORETICAL FRAMEWORK}

For this study, cognitive schema theory provides a framework for describing the cognitive architecture of the mind. In particular, it makes possible a discussion about mental models. As a cognitive constructivist theory of learning, it is mainly oriented at understanding the individual learner's cognitions, while still mindful of the social context in which they exist (Derry, 1996; McVee, Dunsmore, \& Gavelek, 2005).

Cognitive schema theory describes a system for classifying concepts or schema into three general classes, which are useful for conceptualizing and discussing elements of cognitive architecture: (i) memory objects, (ii) mental models, and (iii) cognitive fields (Derry, 1996). A memory object is the basic unit of stored human knowledge and there are three kinds: basic intuitive schemas (i.e., p-prisms), basic knowledge that is complex and structured (e.g., arithmetic schemas), and loosely organized collection of ideas (i.e., object family).

Derry (1996) describes mental models as mental representations of complex situations or problems in which previously learned memory objects are the building blocks for mental models. The process of constructing mental models:

... involves mapping active memory objects onto components of the real-world phenomenon, then reorganizing and connecting those objects so that together they form a model of the whole situation. ... once constructed, a mental model may be used as a basis for further reasoning and problem solving, which may give rise to further readjustments 
to the mental model. ... If two or more people are required to communicate about a situation, they must each construct a similar mental model of it. (Derry, 1996, p. 168)

Cognitive fields, in contrast, are distributed patterns of memory. These patterns arise when certain memory objects are more available than others in response to a particular stimulus (e.g., a posed question). When previous experience is recalled, it activates cognitive fields that then delineate memory objects that are available to mentally model the experience or situation.

The cognitive field thus determines what interpretations and understandings of experience are probable. The cognitive field activated in a learning situation also determines which previously existing memory objects ... can be modified or updated by an instructional experience. (Derry, 1996, p. 168)

\section{METHOD}

his IRB approved exploratory study utilized a pragmatic worldview for conducting research. A research methodology founded on a pragmatic worldview anticipates applications and solutions to problems (Creswell, 2007). The methodology uses methods of data collection and analysis that make sense in the research context, and it is done with the intention of further research which is informed by the immediate research (Creswell, 2003). This study utilizes a qualitative approach to data collection and data analysis. The methodology and methods for this study were reviewed by an expert in education and social science research methodologies and methods, and they were deemed appropriate for the purpose of the study and for answering the specific research questions.

\section{Sample}

This study was conducted at two institutions located in two different states of the United States of America (USA). One is located in the Midwestern state of Nebraska and the other in the Southeastern state of Georgia. Both institutions are Carnegie doctoral-research universities. Both universities had a total student population of $\sim 23,000$ during the time periods of data collection. Given limited project resources and access to potential participants, this study used purposive sampling (Lopez, Atran, Coley, Medin, \& Smith, 1997; Seidler, 1974; Smith, 1983; Zelditch, 1962) to identify students' pre-instructional mental models about groundwater residence (i.e., where groundwater resides and is found in the subsurface). The participants were drawn from four sections of an introductory-level environmental geoscience college course, titled Environmental Geology. One section of the course taught in Georgia drew 107 participants. Three sections of the same course taught in Nebraska drew a total of 108 participants. At both institutions, this course satisfies one or more of each institutions' general education core requirements for science and/or it meets the requirements for a number of geoscience majors at the participating institutions. Demographic data for the two subpopulations and overall population are summarized in Table 1.

Table 1. Participant demographics.

\begin{tabular}{l|c|cc}
\hline \multicolumn{1}{c}{ Demographic } & $\begin{array}{c}\text { Georgia \% } \\
(\mathbf{n = 1 0 7 )}\end{array}$ & $\begin{array}{c}\text { Nebraska \% } \\
(\mathbf{n = 1 0 8})\end{array}$ & $\begin{array}{c}\text { Total \% } \\
(\mathbf{n = 2 1 5})\end{array}$ \\
\hline Male & 54 & 47 & 51 \\
\hline Female & 46 & 53 & 49 \\
\hline First generation college student & 12 & 18 & 15 \\
\hline Freshman & 35 & 42 & 38 \\
\hline Sophomore & 43 & 30 & 36 \\
\hline Junior & 9 & 19 & 14 \\
\hline Senior & 10 & 8 & 9 \\
\hline Standing unknown & 3 & 1 & 2 \\
\hline Geoscience major & 2 & 30 & 16 \\
\hline STEM major & 17 & 34 & 26 \\
\hline Non-STEM major & 83 & 66 & \\
\hline
\end{tabular}




\section{Procedures}

Three sources of data were used to help identify pre-instructional mental models students have about groundwater residence: (i) a short paper-based questionnaire; (ii) brief individual think-aloud interviews; and (iii) a targeted search of the literature. The questionnaire asked:

Draw and label a picture of how water* exists or is naturally stored below the ground surface.

*water that is pumped from below the ground to drink

During the administration of this questionnaire, participants were instructed to clearly draw and label their diagrams to enhance the communication of their ideas. The questionnaire was designed to elicit two different but complimentary ways of communicating the participants' ideas - diagrammatic communication and textual communication. A pilot study with $>300$ students the semester prior to the start of this study was conducted in order to test and revise the questionnaire to ensure that the final questionnaire was interpreted in the manner intended.

The questionnaire was administered in each section at the end of the $8^{\text {th }}$ week of a 15 -week semester. Participants in all four sections did not receive any instruction in this course about groundwater and aquifers before the questionnaire was administered. The questionnaire was administered as part of the regular in-class course work and each student earned two points towards class participation based on the clarity of their answers (i.e., clear drawing with clear labels) and not for correctness.

In addition to the questionnaire, 21 follow-up semi-structured interviews (each lasting 10-15 minutes) were conducted to obtain follow-up information about the mental models captured in the participants' concept sketches. The semistructured interviews flowed from the prompts, "Based on your sketch and annotations, I understand .... Is my understanding right?" and "Can you tell me more about why you think ...?" Ten interviews were conducted in Georgia and 11 in Nebraska. Interviewees were randomly selected from among students who volunteered to participate in the study.

Finally, a targeted search of the literature was conducted to: (i) discover already identified student mental models about groundwater residence and (ii) compare those already identified mental models with those our research identified. Published studies that utilize concept sketches as part of their data collection method were selected for this study because this study's main data collection method involves drawing. In this way, mental models identified by different researchers also using diagrammatic analyses could be reasonably compared. The search for potential articles was conducted using databases maintained by the Education Resources Information Center (ERIC) and Google Scholar. The search was conducted using different combinations of the following search terms: water, groundwater, conceptions, misconceptions, and alternate conceptions.

\section{Analysis}

\section{Questionnaire}

The collected concept sketches were subjected to diagrammatic analysis (Gobert, 2000; Sibley, 2005) and textual content analysis (Sapsford, 1999) using constant comparative analyses to discover categories of mental models. The selected method of constant comparative analysis is an adaptation of the one developed by Strauss and Corbin (1990). First, one researcher defined the unit of analysis that would effectively aid in answering the research questions. Holsti (1969) states that defining the unit of analysis is an essential first-step to systematically analyzing qualitative data. The units of analysis defined for this study are "diagram components" and "text chunk" (Simons, 1993). Each concept sketch and interview could have more than a single diagram component or text chunk. Responses were binned according to their similarities using an iterative constant comparative analysis. 
The method of constant comparative analysis was an iterative process that involved reanalyzing each concept sketch several times, until a stable set of categories emerged. At the end of the analysis, eight categories emerged for the final coding rubric. Each category represents a distinct mental model about groundwater residence.

The categories that emerged were compared with those from the literature, to ensure that similar categories were present for comparison purposes during the data analysis. After the coding rubric was developed, another researcher reviewed it for content, clarity, and organization. The crosschecking with other published studies and the researcherpeer review contributed to the coding rubric's validity and trustworthiness.

One researcher used a process of double-coding (Krefting, 1991) to ensure the repeatability of the results in applying the coding rubric. The two coding sessions were spaced approximately three months apart to allow for a fresh perspective during the second coding session, such that the coding results for each response from the first session were forgotten. There was $>99 \%$ agreement between the results of both coding sessions. Any disparities were contemplated and settled during the second coding session to achieve $100 \%$ agreement. In addition, a second researcher coded $10 \%$ of the responses. The initial interrater reliability was greater than $93 \%$ and $100 \%$ after discussing initially different code assignments.

\section{Interviews}

The collected interview responses $(\mathrm{n}=21)$ underwent a textual content analysis (Sapsford, 1999). Given the relatively small number of interviews and the wide variety of mental models that were represented in the interviews, the interview data does not lend itself to using a constant comparative analyses to discover categories of mental models. Instead, interview data are used to elaborate on the categories of mental models identified in the constant comparative analysis of the concept sketches.

\section{Literature Search}

A targeted search of the literature was conducted for the express purpose of locating peer-reviewed studies that used concept sketches and identified conceptions of groundwater residence in their results. This search was not intended for the purpose of writing a literature review but rather to be able to make some comparisons between the present study's results and other studies' results. To capture as many studies as possible, the academic grade level of a study's participants was not restricted to the college level, the level at which the present study was conducted. Also, studies were not restricted to those that investigated preconceptions only. Studies that examined only conceptions at the end of class instruction or an intervention were also considered suitable for comparison purposes. The main criteria for selecting an article were: (i) part of their methods included concept sketching and (ii) their results at least partly addressed students' ideas about groundwater residence.

\section{Comparison of Pre-Instructional Mental Models Against Expert Model}

The expert mental model that was used in this study as a standard against which to contrast the pre-instructional mental models is the United States Geological Survey's explanation. This explanation addresses the mastery level of understanding targeted in the Environmental Geology course, which is the subject of the larger project that is behind this study. Geoscientists working for the United States Geological Survey describe groundwater in the following way:

Groundwater refers to all subsurface water, specifically that part of groundwater which is in the saturated zone. Groundwater sources are called aquifers: geologic formations that contain sufficient saturated permeable material to yield significant quantities of water to wells and springs. (United States Geological Survey, n.d.)

\section{RESULTS}

\section{Identified Mental Models}

The question about how water is stored naturally in the subsurface is an important one for discovering what students already know about it. Although all students' answers to this question focus on where water is stored in the subsurface, 
these answers are intimately connected to the ideas that students have about how water is stored where it is. From the constant comparative analysis of the concept sketches $(n=215)$, eight categories of pre-instructional mental models about groundwater residence emerged (Table 2). The categories that appear in Table 2 are named with representative language that students used to label their concept sketches. The category labeled "underground reservoirs" also includes concept sketches that students labeled as underground "pockets" and "basins."

Table 2. Summary of student-held pre-instructional mental models about groundwater residence.

\begin{tabular}{l|c|c|c}
\hline \multicolumn{1}{c}{ Category } & Georgia \% $(\mathbf{n = 1 0 7})$ & Nebraska \% $(\mathbf{n = 1 0 8})$ & Total \% \\
\hline Underground lakes & 3 & 2 & 2 \\
\hline Underground caves & 1 & 1 & 1 \\
\hline Underground reservoirs & 43 & 43 & 43 \\
\hline Underground streams & 6 & 9 & 7 \\
\hline Underground layers of water & 44 & 30 & 37 \\
\hline Intermixed with dirt / soil & 6 & 17 & 11 \\
\hline Between small rocks / gravel / sand & 1 & 11 & 6 \\
\hline Inside porous / permeable rock & 2 & 6 & 4 \\
\hline
\end{tabular}

Note: Category names reflect the language students used to label their concept sketches. A single student could express multiple mental models of groundwater residence in one concept sketch, hence the totals for each column do not necessarily sum to $100 \%$.

Based on the concept sketches and interviews, the first three categories listed in Table 2 share two common notions of groundwater residence. The first is that groundwater is stored in cavernous openings of solid rock below the surface. The cavernous openings were conceptualized as being completely or partly filled with water. The second is that the water, once it finds its way into these cavernous openings, does not naturally flow out. Students holding this mental model thought water either "seeped" through the soil or flowed through underground passageways to get into the opening. Students thought the "solid rock" that bounded the opening effectively contained the water and prevented its flow. Collectively, these are the most dominantly held notions associated with groundwater residence (43\% of participants).

The second most dominantly held mental model (37\% of participants) is that groundwater occurs as distinct layers of water in the subsurface. Many students conceptualized these layers of water as being in between other layers of soil, clay, or rock. As with the previously described mental models, students also saw these layers of water as being distinctly contained. The main difference, however, is the morphology of the underground body of water. In the former, water collects in a cavernous opening; whereas, in the latter, the water exists as a horizontal layer. Some students holding the layer-of-water mental model thought these water layers constituted part of the Earth's larger interior structure (i.e., a concentric layer of water below the concentric layer of the Earth's crust).

Seven percent of the students conceptualized groundwater as being stored in "underground streams." This mental model is similar to those previously discussed in that it also hinges on large water-filled openings in solid rock. However, it is distinctly different from those already discussed in that the groundwater is not static but, instead, flows. The following terms were also used to describe naturally-occurring features in the subsurface that were a part of this category of mental model: "passageways," "channels," "fissures," and "canals." Students conceptualized these "underground streams" as flowing both horizontally underground and/or flowing from the surface through the ground, usually into an "underground reservoir."

Eleven percent of the students described groundwater as being "intermixed" with or stored in "dirt" or "soil." Some of these students thought that the groundwater is extracted from the dirt or soil for human consumption using a filtration process. Far fewer students held pre-instructional mental models that involved water being stored in between sediment (e.g., "sand," "gravel," or "small rocks") or inside small openings inside solid rock. Of the pre-instructional mental models that emerged from the analysis of the concept sketches, these two are the most expert. That is, they are the most aligned with the USGS expert definition of groundwater and aquifers.

About $15 \%$ of the students also used what might be considered more technical jargon in the pre-instructional context of an introductory-level course about environmental geology. In particular, there were 34 instances of the use of the word "aquifer" (which was not always spelled correctly) and 16 instances of the use of the term "water table." The 
use of these jargon in a pre-instructional context indicate familiarity with these key hydrological concepts, but do not indicate expert-like mental models. For example, one student noted "water is stored in tables underground." Most students who used these terms used them to label parts of their concept sketches that represent the "underground reservoir" mental model.

\section{Mental Models Reported in Other Studies}

The targeted literature search yielded four studies (Table 3). Note our purpose in identifying additional studies was not to conduct a comprehensive literature review but, instead, to identify a few studies against which to compare our results. The studies we located were conducted in Germany (Reinfried, 2006); Israel (Ben-zvi-Assarf \& Orion, 2005); North Carolina, USA (Dickerson \& Dawkins, 2004); and Arizona, USA (Schwartz, Thomas-Hilburn, \& Haverland, 2011). The participants for these studies spanned different grade levels, from $4^{\text {th }}$ grade to college. The results of these studies are summarized in Table 4. (For ease of comparison, the empirical results of the present study are also included in the Table 4.)

The mental models identified in these four studies were also identified in the present study. They include: underground "lakes," "caves," "reservoirs," "streams," and "inside porous/permeable rock." However, the present study also identified mental models not previously documented: "layer of water" and "intermixed with dirt/soil."

For the most part, the previously published studies do not include the percentage of the population that held an identified mental model. Therefore, it is difficult to infer how prevalent certain mental models are in the studied populations. Also, the foci of these studies do not directly overlap with the focus of this study. Therefore, it is possible that the students in those studies held mental models about groundwater residence that were not recorded or discussed. Nevertheless, Table 4 permits a side-by-side comparison of the results that are available from other studies that used concept sketching to investigate students' ideas about groundwater residence to some degree as a part of their overall work. Importantly, these results help to corroborate the results of the present study and vice versa.

Table 3. Information about studies using concept sketches to gain insights into student thinking about groundwater residence.

\begin{tabular}{l|l|l|l|l|l}
\hline \multicolumn{1}{c|}{ Study } & \multicolumn{1}{|c|}{ A } & \multicolumn{1}{c}{ B } & \multicolumn{1}{c}{ C } \\
\hline Location & Arizona, USA & Israel & $\begin{array}{l}\text { North Carolina, } \\
\text { USA }\end{array}$ & Germany & $\begin{array}{l}\text { Georgia \& } \\
\text { Nebraska, USA }\end{array}$ \\
\hline Grade level & $4^{\text {th }}$ grade & $\begin{array}{l}7-9^{\text {th }} \text { grades } \\
\text { combined }\end{array}$ & $8^{\text {th }}$ grade & college & college \\
\hline Timing of concept sketch & $\begin{array}{l}\text { Post } \\
\text { intervention }\end{array}$ & Pre instruction & & Post instruction \\
\end{tabular}

Notes

${ }^{1 .}$ Concept sketches were collected as part of the evaluation of the Arizona Water Festival program.

2. The purpose of Study B was to identify students' preconceptions about the water cycle.

3. Authors state that no intervention is associated with their study, the concept sketching simply occurred after a class session about groundwater.

${ }^{4}$ Study D tested an instructional intervention and administered pre- and post-intervention tests. Since pre-instructional mental models are the priority for the present study, the results of the pre-test in Study D are used for comparison purposes in the present study. 
Table 4. Comparison of students' mental models about groundwater residence identified in studies in which concept sketching was part of their methods.

\begin{tabular}{|c|c|c|c|c|c|}
\hline $\begin{array}{c}\text { Study } \\
\text { (sample size) }\end{array}$ & $\begin{array}{c}A \\
(n=163)\end{array}$ & $\begin{array}{c}B \\
(n=86)\end{array}$ & $\begin{array}{c}C \\
(n=18)\end{array}$ & $\begin{array}{c}D \\
(n=31)\end{array}$ & $\begin{array}{c}E \\
(n=215)\end{array}$ \\
\hline Lakes & - & $67 \%$ & $\mathrm{Y}$ & $\mathrm{Y}$ & $2 \%$ \\
\hline Streams & - & $\mathrm{Y}$ & $\mathrm{Y}$ & $\mathrm{Y}$ & $7 \%$ \\
\hline Caves & - & - & - & $\mathrm{Y}$ & $1 \%$ \\
\hline Reservoirs & - & - & - & $\mathrm{Y}$ & $43 \%$ \\
\hline Btw small rocks / gravel / sand & $7 \%$ & - & - & - & $6 \%$ \\
\hline Inside porous / permeable rock & - & - & - & $\mathrm{Y}$ & $4 \%$ \\
\hline Intermixed with dirt / soil & - & - & - & - & $11 \%$ \\
\hline
\end{tabular}

Notes

${ }^{1}$ The sample size indicates how many concept sketches were analyzed.

${ }^{2}$. The percentages indicates the percentage of the sample population expressing a given mental model in their concept sketches.

3. The letter ' $\mathrm{Y}$ ' indicates the mental model appeared in the study's results but the percentage of the sample population expressing that mental model could not be determined on the basis of the published information.

4. A dash (-) indicates a given mental model was not mentioned in a given study's results.

\section{DISCUSSION}

\section{Patterns of Mental Models}

Using cognitive schema theory (Derry 1996), connections between the identified mental models and the cognitive architecture of the mind can be made. In particular, the mental models that emerged in this study can be further compared in terms of the patterns of physical water-rock relationships that constitute the mental models about groundwater and aquifers. In the context of cognitive schema theory, the ideas of "water," "rock," and "underground" are memory objects that help build a mental model. Given that aquifers are defined by not only the presence of water underground but also the rock (or other geologic material) in which the water resides (or is mixed with), a comparison of these relationships as they occur in students' mental models can help instructors better understand the variety of students' mental models that exist. This understanding, in turn, can be informative for designing instructional activities with a resource perspective. In this comparison, different relationships between the void space in geologic material and the amount of water that fills the void space emerge.

Specifically, four patterns of mental models emerge: (i) separate pattern, (ii) composite internal pattern, (iii) composite external pattern, and (iv) mixed pattern (Figure 1). Mental models that fall under the separate pattern involve a body of water that is contained in but otherwise separate from the rock (or other geologic material). In these models, large empty voids underground are entirely filled with water. In other words, an aquifer is all water. Mental models that fall under the composite internal pattern involve some water filling the pores spaces inside rock units underground; in other words, an aquifer is composed of water and rock. Mental models that fall under the composite external pattern involve some water filling the void spaces in between sediments that are underground; in other words, here again, an aquifer is composed of water and rock. Lastly, mental models that fall under the mixed pattern involve water intermixed with dirt or soil. In other words, an aquifer is a slurry. Figure 2 shows representative examples of concept sketches that illustrate these patterns of mental models.

Drawing from cognitive schema theory, these four patterns are built on three memory objects: "water," "rock," and "underground" (Figure 1). These memory objects are connected to cognitive fields (i.e., patterns of memory) that, when activated, can be involved in the learning process. For the separate pattern, the memory object "water" mentally invokes ideas of continuous bodies of water. Ideas about continuous bodies of water that students expressed in interviews include, for example, "man-made reservoir," "glass of water," and "rivers." Drawing on these cognitive fields, students metaphorically extend their ideas to the more abstract concepts of groundwater and aquifers, thus mentally visualizing large continuous bodies of water in the subsurface.

For the composite internal and composite external patterns, the memory object "rock" mentally invokes the idea of solid geologic material. In interviews, students stated, "rock is solid" and they articulated their idea that "solid" 
materials are unable to have water inside the material itself. Thus, the memory object "rock" invokes cognitive fields that are incongruent with the scientifically accepted phenomena of rock actually being able to hold water.

Figure 1. Conceptual model of patterns of mental models. Four patterns of mental models about groundwater residence are based on the three dominant memory objects. These four patterns emerge from students' ideas about (i) how large the openings are in the subsurface and (ii) how much water there is.

\begin{tabular}{|c|c|c|c|c|c|}
\hline & & \multicolumn{4}{|c|}{ Dominant Memory Object } \\
\hline & & Water & & & Underground \\
\hline \multirow{3}{*}{ 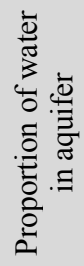 } & All water & 1. Separate pattern & & & \\
\hline & Part water & & $\begin{array}{l}\text { 2. Composite } \\
\text { internal pattern }\end{array}$ & $\begin{array}{l}\text { 3. Composite } \\
\text { external pattern }\end{array}$ & \\
\hline & 'No' water & & & & 4. Mixed pattern \\
\hline & & $\begin{array}{l}\text { Large openings (no } \\
\text { rock) }\end{array}$ & $\begin{array}{l}\text { Small openings } \\
\text { inside rock }\end{array}$ & $\begin{array}{l}\text { Small openings } \\
\text { in between } \\
\text { sediments }\end{array}$ & $\begin{array}{l}\text { No openings } \\
\text { (all slurry) }\end{array}$ \\
\hline & & \multicolumn{4}{|c|}{ Size of opening where groundwater resides } \\
\hline
\end{tabular}

For the mixed pattern, the memory object "underground" mentally invokes ideas of soil or dirt. The memory object "underground" or "below the ground" is associated with cognitive fields that are associated more with typically shallow underground contexts. It is in these shallow underground contexts where students think dirt or soil is found.

Recalling that Norman (1983) stated conceptual models are tools for understanding or teaching, Figure 1 is a conceptual model for understanding students' understanding of groundwater residence. The four patterns of mental models summarized in Figure 1 can be used to (i) more deeply understand students' pre-instructional mental models (Phase 1 of a larger project), and (ii) inform teaching and the design of instructional materials using a resource perspective (Phase 2 of a larger project). Using cognitive schema theory makes possible a deeper understanding of the cognitive underpinnings behind students' preconceptions about groundwater residence. This understanding can, in turn, be used to design instructional activities using a resource perspective. In this way, students' prior knowledge can be used as resources for teaching and learning about groundwater and aquifers. 
Figure 2. Representative examples of students' concept sketches that illustrate the four patterns of mental models.

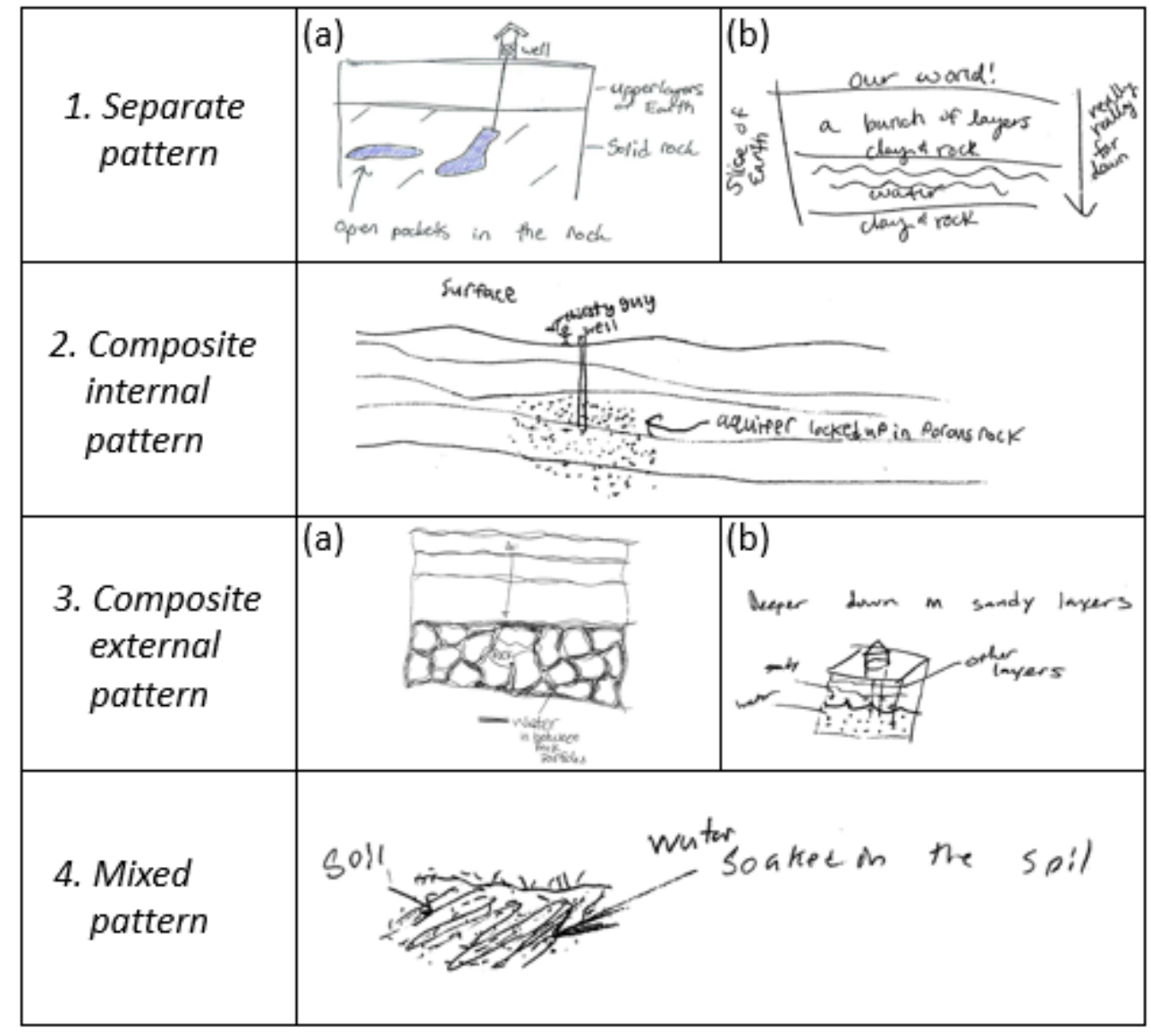

\section{Pre-Instructional Mental Models vs. Expert Mental Model}

Of the patterns of mental models that emerged, the composite internal and composite external patterns are most like the expert mental model for groundwater residence, specifically as aquifers. Only $10 \%$ of the students held these more expert-like mental models prior to instruction.

As previously discussed, the vast majority of students conceptualized groundwater as being stored in underground "lakes," "caves," "reservoirs," or "streams." Technically, these are not incorrect ideas. From a hydrological standpoint, it is possible for groundwater to be stored in large openings underground. This is especially true of regions with karst terrain. Karst aquifers, however, are idiosyncratic instead of general. For example, "about 18\% [of all 50 states in the United States] is underlain by soluble rocks having karst or the potential for the development of karst features" (Weary \& Doctor, 2014, p. 1). Students' understanding of groundwater must move beyond this separate pattern of mental models if they are to be prepared to understand more complex hydrological concepts involving groundwater and aquifers such as residence time, flow rates, mass balance between recharge and discharge, etc.

In particular, students' conception that "solid rock" cannot hold water is a potential hindrance to developing more expert-like mental models of groundwater and aquifers. Based on follow-up interviews to the concept sketching questionnaire, student reasoning about "solid rock" can be summarized as follows: Rocks are solids. Solids do not let water pass through them. An example of this given during an interview was a "water glass ... it holds water but doesn't it let it flow through the glass." If water cannot pass through a solid, then the solid material itself cannot contain water. It is this line of reasoning which supports the separate pattern of mental models. 
The expert mental model of groundwater and aquifers involves rock not only having open spaces (i.e., porous) but also having those open spaces be interconnected (i.e., permeable). These open spaces, however, can be much smaller in scale relative to the most prevalent pre-instructional mental models, which involve very large openings in rock. Furthermore, water is not confined (as many students think) to the interconnected open spaces, the water can move and flow through these open spaces.

The majority of students who participated in this study were freshmen or sophomores and non-geoscience majors. The results of this study revealed a variety of pre-instructional mental models about groundwater and aquifers. Areas where they converge with and deviate from the expert mental model present an opportunity to utilize a resource perspective in teaching about groundwater and aquifers.

\section{Geographic Ubiquity of Mental Models}

Between the results of the present study and the results of the other four studies discussed, two different mental models appear in all but one of the geographic regions from which these data were collected. The mental models that groundwater is stored in underground lakes and/or streams appeared in Israel, Germany, and the United States. Within the United States, they appeared in three different geographical regions - Midwest (Nebraska), Southwest (Arizona), and Southeast (Georgia and North Carolina).

Reasons for this widespread occurrence across grade levels and geographic regions may, at least in part, be explained with Lakoff and Johnson's (1980) finding that individuals' "ordinary conceptual system is metaphorical in nature" (p. 4). It is through the often unconscious cognitive application of metaphor that individuals map familiar schema onto less familiar, more abstract, not yet personally well-developed schema and extend those familiar schema to make sense of and integrate new schema into their existing cognitive frameworks. This supports Meyer's (1987) opinion that, "[f]or the ordinary citizen not directly concerned with groundwater management, equating underground conditions and the surface rivers and lakes with which he is familiar is a simple and efficient way to organized an otherwise confusing set of phenomena" (p. 195).

The mental models represented in Table 3 appeared in at least two different regions and across different grade levels. Thus, it is possible that any learning activities designed to deepen students' understanding of groundwater and aquifers that are based on the mental patterns that emerged from this study might also be relevant to classroom instruction in other regions. It is also possible that that they might be relevant and useful in the instruction of pre-college students.

\section{LIMITATIONS}

Concept sketches communicate key elements of an individual's mental model but do not necessarily communicate all elements that may be present (Clement, 1982; Henriques, 2002; Osborne \& Wittrock, 1983). Drawing to communicate one's ideas has similar goals and limitations to communicating verbally - the goal for clarity and the potential for imperfect conveyance of thoughts exist with both modes of communication. Despite such limitations, drawing has a demonstrated history as a useful tool for studying mental models and cognitive development (e.g.,, Piaget, 1956). The nature of self-report data from the students also introduces limitations, but these are reduced by using accepted research methods, such as the triangulation of multiple sources of data.

\section{CONCLUSION}

- The majority of students participating in this study had pre-instructional mental models about groundwater residence that are largely incongruent with the expert mental model.

- The pre-instructional mental models that students hold vary beyond the "misconception" that groundwater exists in underground lakes and streams (Ben-zvi-Assarf \& Orion, 2005; Mattingly, 1987).

- Using cognitive schema theory to interpret this study's results (i.e., eight categories of mental models) leads to findings (i.e., four patterns of mental models) that are not evident otherwise. The four patterns of mental models are constructed from the memory objects (i.e., students' prior knowledge about): 
"rock," "water," and "underground." These findings can provide a foundation for designing instructional materials that utilize a resource perspective.

- There is some evidence to suggest that the categories and patterns of mental models discussed are relevant in regions and grade levels beyond those in which the empirical components of this study took place. Gauging the geographical ubiquity and persistence across grade levels of these patterns of mental models, therefore, presents areas of potential future research.

- If the discussed categories and patterns of mental models are present in different geographic regions and grade levels, then instructional materials that are developed using this information with a resource perspective could potentially be relevant and have transferability to other courses beyond the introductory-level college course on Environmental Geology for which they were designed (Phase 2 of larger project).

\section{AUTHOR BIOGRAPHY}

Leilani A. Arthurs is an assistant professor in the Department of Geological Sciences at the University of Colorado at Boulder. She has a PhD in Civil Engineering and Geological Sciences and four certificates in pedagogy from the University of Notre Dame. She has worked to transform college science teaching and conduct science education research for more than 10 years. She is a recipient of NSF funding that supports (i) the recruitment and retention of students in the geosciences and (ii) college STEM faculty adoption of research-based instructional strategies. E-mail: Leilani.Arthurs@Colorado.edu (corresponding author)

Justin M. Elwonger holds a Bachelor's degree in Geology and a Master's degree in Science Education both from the University of Nebraska-Lincoln. He is currently a science teacher at Shickley Public Schools in Nebraska. He has four years of cumulative experience conducting science education research at the college and pre-college levels. Emial: jmelwonger@gmail.com

\section{REFERENCES}

Arthurs, L. (2011). What college students think: Student alternate conceptions and their cognitive models of geoscience concepts. In A. D. Feig, \& A. Stokes, (Eds.), Qualitative inquiry in geoscience education research: Geological Society of America special paper 474 (135-152). Boulder, CO: Geological Society of America.

Ausubel, D. P. (1968). Educational psychology: A cognitive view. New York, NY: Holt Rinehart and Winston.

Ausubel, D. P., \& Ausubel, D. P. (2000). The acquisition and retention of knowledge: A cognitive view. Dordrecht: Kluwer Academic Publishers.

Ben-zvi-Assarf, O., \& Orion, N. (2005). A study of junior high students' perceptions of the water cycle. Journal of Geoscience Education, 53(4), 366-373.

Brown, D. E. (1994). Facilitating conceptual change using analogies and explanatory models. International Journal of Science Education, 16(2), 201-214.

Clement, J. (1982). Students' preconceptions elementary mechanics. American Journal of Physics, 50, 66-71.

Clement, J. (1993). Using bridging analogies and anchoring intuitions to deal with students' preconceptions in physics. Journal of research in science teaching, 30(10), 1241-1257.

Creswell, J. W. (2007). Qualitative inquiry and research design: Choosing among five approaches. Thousand Oaks, CA: Sage Publications Inc.

Dal, B. (2007). How do we help students build beliefs that allow them to avoid critical learning barriers and develop a deep understanding of geology? Eurasia Journal of Mathematics, Science \& Technology Education, 3(4), 251-269.

Derry, S. (1996). Cognitive schema theory in constructivist debate. Educational Psychologist, 31(3/4), 163-174.

Dickerson, D., \& Dawkins, K. (2004). Eighth grade students' understandings of groundwater. Journal of Geoscience Education, 52(2), 178-181.

Driver, R. (1981). Pupils' alternative frameworks in science. European Journal of Science Education, 3(1), 93-101.

Driver, R., \& Erickson, G. (1983). Theories-in-action: Some theoretical and empirical issues in the study of students' conceptual frameworks in science. Studies in Science Education, 10(1), 37-60.

Earth Science Literacy Initiative. (2009). Earth science literacy principles. Retrieved from http:// http://www.earthscienceliteracy.org/index.html

Gobert, J. D. (2000). A typology of causal models for plate tectonics: Inferential power and barriers to understanding. International Journal of Science Education, 22, 937-977.

Hammer, D. (2000). Student resources for learning introductory physics. American Journal of Physics, Physics Education Research Supplement, 68(S1), S52-S59. 
Helm, H. (1980). Misconceptions in physics amongst South African students. Physics Education, 15(2), 92.

Henriques, L. (2002). Children's ideas about weather: A review of the literature. School Science and Mathematics, 102(5), 202215.

Hewson, P. W. (1981). A conceptual change approach to learning science. European Journal of Science Education, 3, $383-396$.

Holsti, O. R. (1969). Content analysis for the social sciences and humanities. Reading, MA: Addison-Wesley.

Kenny, J. F., Barber, N. L., Hutson, S. S., Linsey, K. S., Lovelace, J. K., \& Maupin, M. A. (2009). Estimated use of water in the United States in 2005 (No. 1344). US Geological Survey.

Kinchin, I. M., Hay, D. B., \& Adams, A. (2000). How a qualitative approach to concept map analysis can be used to aid learning by illustrating patterns of conceptual development. Educational research, 42(1), 43-57.

Krefting, L. (1991). Rigor in quantitative research: Assessment of trustworthiness. American Journal of Occupational Therapy, 45, 214-222.

Lakoff, G., \& Johnson, M. (1980). Metaphors We Live by. Chicago, IL: University of Chicago Press.

Lopez, A., Atran, S., Coley, J.D., Medin, D.L., \& Smith, E.E. (1997). The tree of life: universal and cultural features of folk biological taxonomies and inductions. Cognitive Psychology, 32, 251-295.

Mackay, D. M., \& Cherry, J. A. (1989). Groundwater contamination: Pump-and-treat remediation. Environmental Science \& Technology, 23(6), 630-636.

Mattingly, R. L. (1987). The dynamics of flowing waters. The Science Teacher, 54, 22-27.

Maupin, M. A., Kenny, J. F., Hutson, S. S., Lovelace, J. K., Barber, N. L., \& Linsey, K. S. (2014). Estimated use of water in the United States in 2010 (No. 1405). US Geological Survey.

McVee, M. B., Dunsmore, K., \& Gavelek, J.R. (2005). Schema theory revisited. Review of Educational Research, 75(4), 531566.

Meyer, H. (2004). Novice and expert teachers' conceptions of learners' prior knowledge. Science Education, 88(6), 970-983.

Meyer, W. B. (1987). Vernacular American theories of earth science. Journal of Geological Education, 35, 193-196.

Norman, D. A. (1983). Some observations on mental models. In D. Gentner \& A. L. Stevens (Eds.), Mental Models, pp. 7-14. Hillsdale, NJ: Laurence Erlbaum Associates, Inc.

Novak, J. D. (1977). A Theory of Education. Ithaca, NY: Cornell University Press.

Osborne, R. J., \& Whittrock, M. C. (1983). Learning science: A generative process. Science Education, 67, 489-908.

Oude Essink, G. H. P. (2001). Improving fresh groundwater supply-problems and solutions. Ocean \& Coastal Management, 44(5/6), 429-449.

Patchen, T., \& Cox-Petersen, A. (2008). Constructing cultural relevance in science: A case study of two elementary teachers. Science Education, 92(6), 994-1014.

Piaget, J. (1956). The child's conception of space. New York, NY: Macmillan Publishers.

Powell, K., \& Kalina, C. (2009). Cognitive and social constructivism: Developing tools for an effective classroom. Education, $130(2), 241-250$.

Reinfried, S. (2006). Conceptual change in physical geography and environmental sciences through mental model building: The example of groundwater. International Research in Geographical and Environmental Education, 15(1), 41-61.

Sapsford, R. (1999). Survey research. London: Sage Publishing.

Savasci, F., \& Berlin, D. (2012). Science teacher beliefs and classroom practice related to constructivism in different school settings. Journal of Science Teacher Education, 23(1), 65-86.

Schwartz, K. L., Thomas-Hilburn, H., \& Haverland, A. (2011). Grounding water: Building conceptual understanding through multimodal assessment. Journal of Geoscience Education, 59, 139-150.

Seidler, J. (1974). On using informants: a technique for collecting quantitative data and controlling measurement error in organization analysis. American Sociological Review, 39, 816-831.

Sibley, D. F. (2005). Visual abilities and misconceptions about plate tectonics. Journal of Geoscience Education, 53, 471-477.

Simons, T. (1993). Speech patterns and the concept of utility in cognitive maps: The case of integrative bargaining. Academy of Management Journal, 36, 139-156.

Smith, T. M. F. (1983). On the validity of inferences from non-random sample. Journal of the Royal Statistical Society. Series A (General), 146, 394-403.

Strauss, A., \& Corbin, J. (1990). Basics of qualitative research: Grounded theory procedures and techniques. Newbury Park, CA: Sage Publishing.

Tweed, A. (2009). Designing effective science instruction: What works in science classrooms. Arlington, VA: NSTA Press.

United States Geological Survey. (n.d.). Groundwater use. Retrieved from http://www.water.usgs.gov/watuse/wugw.html

Wakida, F. T., \& Lerner, D. N. (2005). Non-agricultural sources of groundwater nitrate: A review and case study. Water Research, 39(1), 3-16.

Weary, D. J., \& Doctor, D. H. (2014). Karst in the United States: A digital map compilation and database. US Department of the Interior, US Geological Survey.

Zelditch, M. Jr. (1962). Some methodological problems of field studies. The American Journal of Sociology, 67, 566-576. 


\section{NOTES}

